\title{
RC\&C
}

Revista de Contabilidade e Controladoria

\section{DISTRIBUIÇÃO DO VALOR ADICIONADO EM DIFERENTES CONTEXTOS SOCIETÁRIOS À LUZ DA}

\author{
TEORIA CONTRATUAL DA FIRMA
}

\section{DISTRIBUTION OF ADDED VALUE IN DIFFERENT CORPORATE OWNERSHIP STRUCTURE CONTEXT IN THE LIGHT OF THE THEORY OF THE FIRM IN A CONTRACTUAL PERSPECTIVE}

Recebido em 21.11.2014 | Aceite final em 03.07.2016 |

Nota: este artigo foi aceito pelo Editor Jorge Eduardo Scarpin e passou por uma avaliação double blind review A reprodução dos artigos, total ou parcial, pode ser feita desde que citada a fonte.

Alan Diógenes Góis Mestrando em Administração e Controladoria pela Universidade Federal do Ceará - UFC | Rua Trinta de abril, 254, Castelão, Fortaleza - CE, CEP 60.620-135 | Telefone: (85) 8940-4669 e (85) 3469-4669 | E-mail: alandgois@hotmail.com

Tatiana Aquino Almeida Mestranda em Administração e Controladoria pela Universidade Federal do Ceará UFC | Rua Vicente Linhares, 221/403, Aldeota, Fortaleza - CE, CEP 60.135-270 | Telefone: (85) 9621-7469 e (85) 3047-1043 | E-mail: tatianaaquino.ufc@gmail.com

Juliana Almeida Costa Bacharel em Ciências Contábeis pela Universidade Federal do Ceará - UFC | Rua Raul Nabuco, 36, Bonsucesso, Fortaleza - CE, CEP 60.520-794 | Telefone: (85) 86497754 e (85) 3496-1588 | E-mail: juliana_costa92@hotmail.com

Márcia Martins Mendes De Luca Doutora em Controladoria e Contabilidade pela Universidade de São Paulo - USP | Professora Associada da Universidade Federal do Ceará - UFC | Rua Coronel Jucá, 1000/1501, Aldeota, Fortaleza - CE, CEP 60.170-320 | Telefone: (85) 8614-8899 e (85) 3261-1705 | E-mail: marciadeluca@ufc.br 
Alessandra Carvalho de Vasconcelos

Doutora em Engenharia de Produção pela Universidade Federal de Santa Catarina UFSC | Professora Adjunta da Universidade Federal do Ceará - UFC | Rua Carlos Vasconcelos, 2852/1701, Dionísio Torres, CEP 60.115-171, Fortaleza - CE Telefone: (85) 9921-8876 e (85) 3034-1296 | E-mail: alevasconcelos.ufc@gmail.com

\section{RESUMO}

Com base na influência do contexto societário das empresas perante seus stakeholders, aliado às novas exigências dos usuários da informação contábil, e sob o arcabouço da Teoria Contratual da Firma, a presente pesquisa tem por objetivo analisar a relação entre a distribuição do valor adicionado das empresas entre os principais agentes contratuais empregados, governo, financiadores e proprietários - e o seu contexto societário. Para tanto, realizou-se uma análise descritiva, com abordagem quantitativa, com base em uma amostra que reúne 99 empresas, classificadas pela revista Exame Melhores e Maiores, edição 2013, entre as 100 maiores companhias abertas do Brasil por valor de mercado. Os dados coletados referem-se aos exercícios de 2010, 2011 e 2012, foram extraídos das demonstrações financeiras padronizadas e formulários de referência disponíveis no portal eletrônico da BM\&FBovespa, e tratados por meio da Correlação de Pearson e da Análise de Correspondência Múltipla. Os resultados demonstraram que (i) empresas pequenas e do setor comércio distribuem parcela maior da riqueza com os empregados e as empresas médio-pequenas e do setor serviço possuem uma maior preocupação com o proprietário; (ii) a distribuição do valor adicionado para os empregados apresentou relação negativa com o contexto societário estrangeiro; (iii) a destinação da riqueza para o governo apresentou relação negativa com o contexto societário familiar e positiva com os contextos societários estatal e estrangeiro; (iv) a parcela da riqueza gerada para os financiadores mostrou relação positiva com o contexto societário estrangeiro; e (v) a distribuição da riqueza com os proprietários demonstrou relação positiva com o contexto societário familiar e negativa com o contexto societário estrangeiro. Conclui-se que o contexto societário, representado pelo maior acionista controlador, influencia a distribuição do valor adicionado com os principais agentes contratuais das empresas, aceitando-se a hipótese geral do estudo.

Palavras Chave: Valor Adicionado. Contexto Societário. Teoria Contratual da Firma.

\section{ABSTRACT}

Based on the influence of the corporate ownership structure context of companies towards their stakeholders, combined with new user's demands of accounting information, and within the framework of the Firm's Contract Theory, the present research aims at analyzing the relation between the 


\begin{abstract}
distribution of added value by companies among major contract agents employees, government, financiers and owners - and their ownership structure context. In order to do so, a descriptive analysis was realized, with a quantitative approach, based on a sample which gathers 99 companies, classified in the 2013 issue of Exame Melhores e Maiores Magazine as the 100 largest Brazilian public companies by market value. The collected data referring to the exercises of 2010, 2011 and 2012 have been excerpted from standard financial statements and reference application forms available at the BM\&FBovespa website and have been treated by means of Pearson's Correlation and Multiple Correspondence Analysis. Results demonstrate that (i) small companies in the trading sector distribute a larger share of wealth to their employees and small-medium companies of service sector display greater preoccupation with owners; (ii) the distribution of added value for employees presented negative relation with the foreign ownership structure context; (iii) the destination of wealth to the government presented negative relation with the family ownership structure context and a positive relation with the foreign and state ownership structure contexts; (iv) the share of wealth produced for financiers displayed positive relation with the foreign corporate ownership structure ; and ( $v$ ) the distribution of wealth among owners presented positive relation with the family corporate context and negative relation with the foreign context. It has been concluded that the corporate ownership structure context, represented by the major shareholder, influences the distribution of added value to the most important contract agents in companies, and the study's general hypothesis was accepted.
\end{abstract}

Keywords: Added Value. Corporate Ownership Structure Context; Contractual Theory of the Firm.

\section{INTRODUÇÃO}

O adequado fornecimento de informações aos usuários, para subsidiar suas decisões, é o principal objetivo da contabilidade, que se encontra em contínua evolução e adaptação às mudanças socioeconômicas ocorridas no ambiente (BRAGA, 2008). Dessa forma, os usuários da informação contábil se tornam mais exigentes, o que enseja, assim, mudanças para que a cada dia essas informações sejam mais completas e úteis à tomada de decisão (BARBOSA et al., 2012).

Nesse cenário, a Demonstração do Valor Adicionado (DVA) surgiu como uma das ferramentas para atender às novas exigências dos usuários das demonstrações contábeis. Segundo Fonseca e Paiva (2012), a DVA informa sinteticamente o desempenho socioeconômico da empresa, evidenciando a riqueza gerada e sua distribuição com os stakeholders. A DVA surgiu na Europa na década de 1970, e, apesar de divulgar dados relevantes, não é obrigatória em todos os países (EVRAERT; RIAHIBELKAOUI, 1998; PINTO; FREIRE, 2013). No que diz respeito ao Brasil, verifica-se que, com a promulgação da Lei $n^{\circ} 11.638 / 2007$ (BRASIL, 2007), a DVA passou a ser obrigatória para as empresas de capital aberto a partir de 2009 (SILVA; HAUSSMANN; BEUREN, 2012). Para orientar a sua elaboração e divulgação, o Comitê de Pronunciamentos Contábeis (CPC) emitiu o Pronunciamento Técnico CPC 09 (CPC, 2008), que trata especificamente da DVA.

Dentre outras perspectivas de análise e compreensão da DVA, destaca-se certa vinculação com a Teoria Contratual da Firma (SCHERER, 2006). Considerando os preceitos dessa teoria, as empresas 
são vistas como um nexo de contratos, no qual um grupo de stakeholders reconhece que seu bemestar depende do sucesso da firma em competição com outras. Destarte, tais indivíduos contribuem com algum recurso para o processo de produção da firma, na expectativa de obter um retorno sobre seu investimento (PEREIRA et al., 2010). Vale ressaltar que qualquer relação entre a organização e seus participantes é estabelecida por meio de contrato, explícito ou implícito, sendo que ambos os tipos de contrato caracterizam o relacionamento entre as partes (LOPES; MARTINS, 2012).

Na medida em que a Teoria Contratual da Firma define as organizações como um conjunto de contratos, há, portanto, uma conexão com a proposta da DVA, a qual procura evidenciar a contribuição dos principais stakeholders (empregados, governo, financiadores e proprietários) na geração e distribuição da riqueza das empresas (SCHERER, 2006). Assim, esses stakeholders são os principais grupos de agentes ou indivíduos com que a entidade estabelece contratos. Desse modo, verifica-se a importância da relação contratual entre esses agentes e a organização com a qual se relacionam, sendo essa importância traduzida pelas informações apresentadas na DVA.

Contudo, ressalta-se ainda que, em conformidade com as considerações de Santos, Chan e Silva (2007), Braga (2008) e Machado et al. (2009), dependendo do contexto societário da empresa, a geração e a distribuição da riqueza entre os seus principais agentes contratuais pode ser diversificada. Dessa forma, busca-se uma resposta para a seguinte questão: Qual a relação entre a distribuição do valor adicionado das empresas entre os principais agentes contratuais e o seu contexto societário?

No presente estudo, entende-se por contexto societário o tipo de controle do capital, estudado por meio da identidade do maior acionista controlador. Dessa forma, com base nos pressupostos da Teoria Contratual da Firma, levanta-se a seguinte hipótese: a distribuição do valor adicionado entre os principais agentes contratuais - empregados, governo, financiadores e proprietários - das empresas está relacionada com o seu contexto societário.

O estudo tem como objetivo geral analisar a relação entre a distribuição do valor adicionado com os principais agentes contratuais das empresas e o seu contexto societário. Adicionalmente, procurouse verificar a associação entre o setor de atividade econômica, o tamanho da firma e a distribuição do valor adicionado.

O estudo apresenta uma abordagem quantitativa, em que se utilizaram 297 observações, de uma amostra de 99 empresas classificadas pela revista Exame Melhores e Maiores, edição de 2013, entre as 100 maiores empresas de capital aberto do Brasil por valor de mercado. A coleta dos dados referente à distribuição do valor adicionado, contexto societário, tamanho da firma e setor econômico foi efetuada a partir das demonstrações financeiras padronizadas e de formulários de referência, dos exercícios findos em 31/12/2010, 31/12/2011 e 31/12/2012, disponíveis no portal eletrônico da Bolsa de Valores, Mercadorias e Futuros (BM\&FBovespa).

Este estudo se justifica na medida em que a Teoria Contratual da Firma ainda é pouco estudada quando associada à DVA, e, além disso, o estudo considera o contexto societário em que as empresas estão inseridas. Justifica-se ainda pela obrigatoriedade da elaboração e divulgação da DVA pelas empresas de capital aberto no Brasil (Lei no 11.638/2007) e pela sua importância no conjunto de demonstrações contábeis que devem ser apresentadas aos usuários externos, em conformidade com Costa, Guimarães e Mello (2013), que destacam o poder informativo trazido pela DVA no que concerne à geração de riqueza pelas empresas e sua distribuição aos agentes econômicos.

\section{DISTRIBUIÇÃO DO VALOR ADICIONADO E CONTEXTO SOCIETÁRIO}


Considerando os preceitos da Teoria Contratual da Firma, a empresa pode ser concebida como um nexo de contratos entre os diversos participantes, cuja estrutura varia de modo previsível, de acordo com variáveis passíveis de análise, pautadas por regras institucionais (ZYLBERSTAJN, 2005; LOPES, IUDÍCIBUS, 2012).

Desse modo, segundo Lopes e ludícibus (2012), cada participante contribui com algo para a firma, a fim de receber algo em troca, sendo necessário um equilíbrio contratual para o funcionamento adequado da empresa. Ou seja, a empresa mantém contratos entre as partes que são necessárias para a sua existência; assim, tais contratos devem se manter harmônicos, pois o mau funcionamento da relação contratual pode prejudicar as atividades da empresa.

No contexto da Teoria Contratual da Firma, a contabilidade, de acordo com Sunder (2014), possui cinco funções na coordenação dos vários contratos existentes entre a empresa e suas partes, a saber: (1) mensurar a contribuição de cada participante da empresa; (2) mensurar o incentivo recebido por cada um dos participantes da empresa; (3) comparar as contribuições e os incentivos recebidos por cada participante com a parcela demonstrada nos contratos; (4) manter um mercado líquido para as participações contratuais e para os fatores de produção fornecidos por seus ocupantes; e (5) distribuir essas informações a todos os participantes.

Dentre os principais demonstrativos contábeis produzidos pelas empresas no Brasil, a Demonstração do Valor Adicionado (DVA) se enquadra nas funções da contabilidade delimitadas por Sunder (2014), à luz da Teoria Contratual da Firma (SCHERER, 2006). Para tanto, faz-se necessário apresentar uma breve contextualização sobre a DVA.

A DVA eclodiu na Europa durante a década de 1970, principalmente por influência da Inglaterra, França e Alemanha (EVRAERT; RIAHI-BELKAOUI, 1998; SCHERER, 2006; FREGONESI, 2009), pois a informação contábil tradicional se tornou insuficiente para atender às novas demandas dos usuários que apresentam interesses diversos dos contemplados nos demonstrativos clássicos (COZENSA, 2003). No Brasil, a DVA surgiu nos anos 1990, tornando-se obrigatória para as companhias abertas somente em 2009, a partir da promulgação da Lei $n^{\circ}$ 11.638/2007 (SILVA; HAUSSMANN; BEUREN, 2012).

Na concepção de Santos (2007) e Santos et al. (2013), a DVA é a forma mais eficiente desenvolvida pela contabilidade para apoiar a mensuração e demonstração da capacidade de geração, assim como de distribuição da riqueza de uma empresa. Complementando tal ideia, Pinto e Freire (2013) destacam que a DVA sinaliza a política adotada pela empresa frente a seus diversos grupos de interesse, além de divulgar dados macroeconômicos. Em outras palavras, Vasconcelos et al. (2013) mencionam que a DVA é vista como uma nova dimensão de informação para os stakeholders, em comparação com os demonstrativos tradicionais, pois estes sempre tiveram por finalidade divulgar informações econômicas sobre as empresas, em atendimento principalmente aos interesses de seus proprietários e ao governo.

A pesquisa de Costa, Guimarães e Mello (2013), que avaliou o poder informativo trazido pela DVA no que concerne à geração de riqueza pelas empresas e sua distribuição aos agentes econômicos, concluiu que a publicação da DVA pelas empresas no Brasil constitui um excelente avaliador da distribuição da riqueza das empresas para a sociedade, proporcionando a comparação dos indicadores entre empresas do mesmo setor, e gerando um aumento das informações das entidades à disposição dos seus usuários e partes interessadas.

De Luca et al. (2009) asseveram que a DVA tem por objetivo identificar e evidenciar o valor da riqueza gerada pela empresa e como essa riqueza foi distribuída entre os agentes econômicos que colaboraram para sua geração. Logo, a DVA divulga duas informações básicas em sua apresentação: a 
criação da riqueza, ou valor adicionado gerado, e a distribuição dessa riqueza, também denominada valor adicionado distribuído.

$O$ valor adicionado compreende o quanto a entidade agrega de valor sobre o que ela destina a terceiros (RIAHI-BELKAOUI; FEKRAT, 1994; VIEIRA, 2004), de modo geral, mensurado pela diferença entre as vendas e os insumos obtidos de terceiros (SANTOS, 2007; DE LUCA et al., 2009). Ou seja, o valor adicionado corresponde à soma de toda a remuneração dos esforços empreendidos no desempenho das atividades da organização (COZENSA, 2003; BRAGA, 2008).

Trata-se, portanto, de um relatório contábil que divulga tanto os benefícios que as organizações proporcionam à sociedade quanto a sua capacidade de colaborar para o desenvolvimento econômico. Mostra ainda um mapeamento de como essa riqueza é distribuída aos seus diversos componentes, tais como empregados, governo, financiadores, proprietários (CUNHA; RIBEIRO; SANTOS, 2005).

Conforme orienta o Comitê de Pronunciamentos Contábeis (CPC), no Pronunciamento Técnico CPC 09 (CPC, 2008), a DVA deve apresentar a seguinte estrutura: Receitas; Insumos adquiridos de terceiros; Valor adicionado bruto; Depreciação, amortização e exaustão; Valor adicionado líquido produzido pela entidade; Valor adicionado recebido em transferência; Valor adicionado total a distribuir; e Distribuição do valor adicionado, compreendendo pessoal (empregados), impostos, taxas e contribuições (governo), remuneração do capital de terceiros (financiadores) e remuneração do capital próprio (proprietários).

Os elementos que fazem parte da distribuição da riqueza na DVA com cada tipo de stakeholder empregados, governo, financiadores e proprietários - são mostrados no Quadro 1.

Quadro 1 - Distribuição da riqueza entre os stakeholders

\begin{tabular}{|c|c|}
\hline Stakeholder & Descrição \\
\hline Empregados & $\begin{array}{l}\text { Remuneração direta - valores relativos a salários, 13ㅇ salário, honorários da administração, } \\
\text { férias, comissões, horas extras, participação de empregados nos resultados, etc. } \\
\text { Benefícios - representados pelos valores relativos à assistência médica, alimentação, } \\
\text { transporte, planos de aposentadoria etc. } \\
\text { FGTS - valores depositados em conta vinculada dos empregados }\end{array}$ \\
\hline Governo & $\begin{array}{l}\text { Federais - tributos devidos à União, inclusive aqueles que são repassados no todo ou em } \\
\text { parte aos estados, municípios, autarquias etc., tais como IRPJ, CSSL, IPI, CIDE, PIS, Cofins e } \\
\text { Contribuição sindical patronal } \\
\text { Estaduais - tributos devidos aos estados, inclusive aqueles que são repassados no todo ou } \\
\text { em parte aos municípios, autarquias etc., tais como ICMS e IPVA. } \\
\text { Municipais - tributos devidos aos municípios, inclusive aqueles que são repassados no todo } \\
\text { ou em parte às autarquias, ou quaisquer outras entidades, tais como ISS e IPTU }\end{array}$ \\
\hline Financiadores & $\begin{array}{l}\text { Juros - as despesas financeiras, inclusive as variações cambiais passivas, relativas a } \\
\text { quaisquer tipos de empréstimos e financiamentos junto a instituições financeiras, empresas } \\
\text { do grupo ou outras formas de obtenção de recursos } \\
\text { Aluguéis - os aluguéis pagos ou creditados a terceiros (inclusive as despesas com } \\
\text { arrendamento operacional), inclusive os acrescidos aos ativos } \\
\text { Outras - outras remunerações que configurem transferência de riqueza a terceiros, mesmo } \\
\text { que originadas em capital intelectual, tais como royalties, franquia e direitos autorais }\end{array}$ \\
\hline Proprietários & $\begin{array}{l}\text { Juros sobre o capital próprio (JCP) e dividendos - valores pagos ou creditados aos sócios e } \\
\text { acionistas por conta do resultado do período, ressalvando-se os valores dos JCP transferidos } \\
\text { para a conta de reserva de lucros } \\
\text { Lucros retidos e prejuízos do exercício - valores relativos ao lucro do exercício destinados às } \\
\text { reservas, inclusive os JCP quando tiverem esse tratamento; nos casos de prejuízo, esse valor } \\
\text { deve ser incluído com sinal negativo }\end{array}$ \\
\hline
\end{tabular}

Fonte: Adaptado do CPC 09 (2008). 
Como mostra o Quadro 1, a DVA demonstra a remuneração aos vários agentes econômicos, representados pelos principais contratos da empresa: empregados, governo, financiadores e proprietários.

Por meio das informações disponibilizadas na DVA, esses grupos de stakeholders podem assumir um papel mais dinâmico na tomada de decisão, na medida em que são capazes de verificar, por exemplo, (a) se a entidade está gerando um montante de riqueza satisfatório; (b) se essa riqueza apresenta crescimento no decorrer do tempo; e (c) se sua parcela na distribuição do valor adicionado é apropriada (SCHERER, 2006). Dessa forma, os stakeholders passam a usufruir de condições que lhes possibilitam fazer um real acompanhamento da atuação de uma entidade no ambiente em que está inserida, avaliando como ela reparte o bolo de sua riqueza (VIEIRA, 2010).

No Brasil, foram realizados diversos estudos no intuito de analisar a DVA. A partir da pesquisa bibliográfica realizada, observa-se que os enfoques também são bastante variados, abrangendo desde a identificação das vantagens da sua utilização como instrumento de avaliação da distribuição de riqueza pelas empresas, até estudos que visam propiciar uma melhor compreensão da DVA. A seguir, apresentam-se alguns estudos que, de alguma forma, se relacionam com a presente pesquisa, pois contemplam a DVA em diferentes contextos societários.

Cunha, Ribeiro e Santos (2005) avaliaram o poder de aferição da DVA, no que concerne a informações sobre a formação de riqueza pelas empresas e sua distribuição aos agentes econômicos que ajudaram a criá-la, como proprietários, sócios e acionistas, governo, financiadores externos e empregados. Os autores concluem que a DVA é uma demonstração contábil que tem força própria, pois contém informações que sozinhas são conclusivas e úteis aos stakeholders, e que os indicadores obtidos a partir dessa demonstração se constituem num excelente avaliador da distribuição da riqueza da firma, no entanto, sem a pretensão de substituir os indicadores já existentes, ou até mesmo, rivalizar, com eles.

Chan, Silva e Martins (2007) investigaram a destinação da riqueza aos acionistas e aos empregados em empresas estatais e privadas. Os autores identificaram que as entidades privadas destinaram menor proporção da riqueza aos empregados, comparativamente às estatais, embora não tenham sido encontrados indícios de que remunerem mais os acionistas, diferindo de alguns estudos assemelhados.

Santos, Chan e Silva (2007) procuraram identificar, com base na amostra final de oito empresas, os possíveis impactos da privatização sobre a distribuição de riqueza das entidades, utilizando como base a DVA. Dessa forma, foi feita uma comparação do valor adicionado gerado e distribuído pelas empresas antes e depois da alienação do seu controle acionário. Quanto à geração de riqueza, constatou-se que o desempenho dessas empresas melhorou significativamente. Dentre os principais resultados encontrados pelos autores, verificou-se uma expressiva redução dos gastos com empregados.

Braga (2008) realizou uma comparação entre a distribuição de riqueza realizada por dois tipos de empresa: privadas e estatais. A amostra desse estudo foi composta por 20 empresas brasileiras, sendo 10 estatais e 10 privadas, que realizaram a publicação da DVA nos anos de 2002 a 2006, período no qual ainda não havia exigência de sua divulgação. A análise dos resultados revelou que não há diferença significante entre os dois tipos de empresa para empregados, financiadores e proprietários, sendo que, para o último grupo, esse resultado foi encontrado apenas para os itens juros sobre o capital próprio e dividendos. Contudo, verificou-se uma significativa diferença entre empresas privadas e estatais quanto à distribuição de riqueza aos stakeholders governo e proprietários, no item lucros retidos/prejuízo do exercício. 
Follmann, Casagrande e Paiva (2009) analisaram a distribuição do valor adicionado em empresas brasileiras que negociam ações na BM\&FBovespa. Os resultados demonstraram que as empresas destinaram maior proporção da riqueza para a conta Pessoal, seguida por Remuneração de Capitais de Terceiros, Impostos, Taxas e Contribuições e Remuneração de Capital Próprio.

O estudo realizado por Machado et al. (2009) objetivou verificar se, na amostra de 198 empresas, em que se analisa a DVA e o Balanço Social para o período de 2004 a 2007, há diferenças entre empresas privadas e estatais, atuantes no setor elétrico, quanto à destinação de riqueza aos empregados. Por meio da aplicação de técnicas estatísticas, verificou-se que as empresas estatais registram gastos com pessoal mais elevados do que os das empresas privadas, sendo o determinante dessa diferença a quantidade de empregados, além da elevada remuneração, percebida a partir do ano 2006.

Os resultados da pesquisa de Santos e Silva (2009) - que teve por objetivo analisar a distribuição do valor adicionado gerado nas empresas pertencentes ao setor de telefonia no Brasil, nos anos de 2007 e 2008 - apontam que, nos dois anos analisados, o governo é o stakeholder para o qual se destina a maior proporção da riqueza, seguindo-se os financiadores, os acionistas e os empregados.

Boscov e Bispo (2010) analisaram a distribuição da riqueza criada e evidenciada em 3.378 demonstrações de empresas dos setores comércio, indústria e serviço, do período de 1997 a 2006, retiradas do banco de dados da revista Exame Melhores e Maiores. Os autores constataram que as empresas do setor serviço proporcionam, em média, maior remuneração a seus credores, enquanto os empregados das empresas do setor industrial são os que recebem a menor participação na riqueza. Os setores comércio e serviço apresentam diferenças significativas quanto ao percentual de riqueza distribuída aos credores e quanto à parcela de lucro que fica retida nas empresas. Verificouse ainda diferença entre os três setores analisados quando à distribuição aos acionistas (pagamento de juros sobre o capital próprio e dividendos).

O estudo realizado por Follmann, Paiva e Soares (2010) procurou analisar a distribuição do valor adicionado nas sociedades anônimas de capital aberto pertencentes ao segmento de listagem Novo Mercado, da BM\&FBovespa, nos anos de 2008 e 2009, reunindo uma amostra de 90 empresas, distribuídas em 10 setores de atuação. A análise setorial demonstrou que, nos dois anos estudados, o item "Impostos, Taxas e Contribuições" foi o mais representativo na maioria dos setores. Vale destacar que, ao se realizar uma análise consolidada, as empresas registraram como itens mais representativos "Pessoal", em 2008, e "Impostos, Taxas e Contribuições" em 2009.

Cabe destacar que o contexto societário, na presente pesquisa, é estudado por meio da identidade do maior acionista controlador, que é uma das áreas de estudo da estrutura de propriedade. A estrutura de propriedade é uma característica marcante no mercado acionário brasileiro. Destacando a influência da estrutura de propriedade, Dani et al. (2013) verificaram que ela pode definir a proporção de investimentos socialmente responsáveis, bem como sofrer influência do corpo diretor da firma e ainda de outras empresas sustentáveis.

Segundo Campos (2006), as empresas brasileiras de capital aberto têm como característica a grande concentração de capital e o pequeno número de acionistas com grande parte do controle acionário. Uma das consequências dessa alta concentração acionária é o monopólio do processo decisório da empresa por parte dos controladores (CAIXE; KRAUTER, 2013). De acordo com o Instituto Brasileiro de Governança Corporativa (IBGC, 2009), tais controladores podem assumir diferentes identidades, dentre as seguintes modalidades: estatal, familiar, estrangeiro e institucional.

Pedersen e Thomsen (2003) asseveram que a identidade do controlador é um fator que determina quais são seus objetivos e preferências em relação à empresa; Okimura, Silveira e Rocha (2007) afirmam que o desempenho das empresas pode se diferenciar, dependendo do tipo de controlador. Nessa mesma perspectiva, destacam-se os estudos aqui já mencionados que também revelam 
diferenças quanto à distribuição do valor adicionado, dependendo do contexto societário da empresa (SANTOS; CHAN; SILVA, 2007; BRAGA, 2008; MACHADO et al., 2009).

Para esta pesquisa, adotou-se a classificação de diferentes contextos societários de Carvalhal-da-Silva (2004), Leal e Carvalhal-da-Silva (2005), Dami, Rogers e Ribeiro (2007) e IBGC (2009) quanto à caracterização dos controladores das empresas, classificando-os em estatal, familiar, estrangeiro e institucional.

\section{PROCEDIMENTOS METODOLÓGICOS}

O presente estudo se enquadra como pesquisa descritiva, na medida em que visa identificar e obter informações sobre as características de um problema (COLLIS; HUSSEY, 2005), mais especificamente a relação entre a distribuição do valor adicionado com os principais agentes contratuais das empresas e o seu contexto societário. É considerada quantitativa, quanto à abordagem, pois utiliza a coleta de dados para testar hipóteses com base na medição numérica, além de utilizar a análise estatística para estabelecer padrões de comportamento (SAMPIERI; COLLADO; LÚCIO, 2013). Por utilizar materiais não editados, é considerada documental, em relação aos procedimentos (MARTINS; THEÓPHILO, 2009).

A amostra do estudo reúne 99 das 100 maiores empresas de capital aberto do Brasil por valor de mercado, segundo a revista Exame Melhores e Maiores, edição 2013. A empresa Amil foi excluída da amostra inicial por ter fechado o capital depois da publicação do ranking e antes da coleta dos dados da presente pesquisa. O estudo contemplou 297 observações das 99 empresas da amostra, referentes ao período de 2010 a 2012.

Inicialmente foi realizada uma análise descritiva da distribuição do valor adicionado das empresas, em que foram observadas a proporção por agente contratual e por período analisado e a proporção por agente contratual e por contexto societário.

Quanto ao fator contexto societário, este estudo utiliza como proxy a identidade do maior acionista controlador. Baseando-se em Carvalhal-da-Silva (2004), a identidade do maior acionista controlador foi rastreada até que fosse possível classificá-lo em um dos seguintes grupos: (i) indivíduos ou famílias, (ii) investidores estrangeiros (tanto indivíduos quanto instituições), (iii) governo e (iv) investidores institucionais (bancos, companhias de seguros, fundos de pensão ou fundos de investimento). Esses grupos são denominados, nesse estudo, como familiar, estrangeiro, estatal e institucional, respectivamente.

No âmbito da Teoria Contratual da Firma, Lopes e ludícibus (2012) asseveram que cada stakeholder, por meio de contratos, contribui com algo para a firma, a fim de receber algo em troca. Desse modo, a participação de cada um deles na riqueza gerada pode ser determinada pelo contexto societário, na medida em que a alta concentração acionária define os objetivos e as preferências da empresa (PEDERSEN; THOMSEN, 2003), podendo diferenciar a riqueza gerada (OKIMURA; SILVEIRA; ROCHA, 2007). Nesse sentido, a hipótese do estudo é: a distribuição do valor adicionado com os principais agentes contratuais - empregados, governo, financiadores e proprietários - das empresas está relacionada com o seu contexto societário.

Considerando cada grupo de agentes contratuais, apresentam-se as seguintes hipóteses específicas:

H1a: A distribuição do valor adicionado com os empregados das empresas está relacionada com o contexto societário.

H1b: A distribuição do valor adicionado com o governo está relacionada com o contexto societário. 
H1c: A distribuição do valor adicionado com os financiadores está relacionada com o contexto societário.

H1d: A distribuição do valor adicionado com os proprietários das empresas está relacionada com o contexto societário.

O teste estatístico empregado para confirmar ou refutar a hipótese do estudo foi a Correlação de Pearson. Segundo Moore (2007), a correlação demonstra a relação, positiva ou negativa, e o grau dessa relação entre duas variáveis quantitativas. Quanto ao grau de relação entre as variáveis, Dancey e Reidy (2006) versam que, se o coeficiente for até 0,30 considera-se uma relação fraca, se for entre 0,40 até 0,60 é considerada uma relação moderada, e se for maior que ou igual 0,70 é considerada uma relação forte. O Quadro 2 apresenta as variáveis utilizadas no teste de Correlação de Pearson.

Quadro 2 - Variáveis do teste de correlação

\begin{tabular}{|c|c|c|}
\hline Grupo de variáveis & Operacionalização & Fonte de coleta \\
\hline Empregados & $\begin{array}{l}\text { Quociente entre o valor distribuído para } \\
\text { Empregados e o Valor Adicionado Total }\end{array}$ & \multirow{4}{*}{$\begin{array}{l}\text { Demonstração do Valor } \\
\text { Adicionado }\end{array}$} \\
\hline Governo & $\begin{array}{l}\text { Quociente entre o valor distribuído para Governo e o } \\
\text { Valor Adicionado Total }\end{array}$ & \\
\hline Financiadores & $\begin{array}{l}\text { Quociente entre o valor distribuído para } \\
\text { Financiadores e o Valor Adicionado Total }\end{array}$ & \\
\hline Proprietários & $\begin{array}{l}\text { Quociente entre o valor distribuído para } \\
\text { Proprietários e o Valor Adicionado Total }\end{array}$ & \\
\hline Estatal & $\begin{array}{l}\text { Variável dummy: } 1 \text { para empresas que possuem } \\
\text { maior acionista controlador estatal e } 0 \text { para as } \\
\text { demais }\end{array}$ & \multirow{4}{*}{$\begin{array}{l}\text { Item } 15.1 / 2 \text { do Formulário } \\
\text { de Referência }\end{array}$} \\
\hline Estrangeiro & $\begin{array}{l}\text { Variável dummy: } 1 \text { para empresas que possuem } \\
\text { maior acionista controlador estrangeiro e } 0 \text { para as } \\
\text { demais }\end{array}$ & \\
\hline Familiar & $\begin{array}{l}\text { Variável dummy: } 1 \text { para empresas que possuem } \\
\text { maior acionista controlador familiar e } 0 \text { para as } \\
\text { demais }\end{array}$ & \\
\hline Institucional & $\begin{array}{l}\text { Variável dummy: } 1 \text { para empresas que possuem } \\
\text { maior acionista controlador institucional e } 0 \text { para as } \\
\text { demais }\end{array}$ & \\
\hline
\end{tabular}

Fonte: Elaborado pelos autores.

Para atender ao objetivo adicional da pesquisa - verificar a associação entre o setor de atividade econômica, o tamanho da firma e a distribuição do valor adicionado -, o estudo utiliza a Análise de Correspondência Múltipla, que, segundo Fávero et al. (2009, p. 272), "é uma técnica que exibe as associações entre um conjunto de variáveis categóricas não métricas em um mapa perceptual, permitindo, dessa maneira, um exame visual de qualquer padrão ou estrutura de dados". Para realizar a Anacor, deve-se primeiramente realizar o teste Qui-quadrado para verificar a associação entre as variáveis.

Devido à Análise de Correspondência Múltipla utilizar somente variáveis categóricas não métricas, o tamanho da firma e a distribuição do valor adicionado foram transformados. Inicialmente, os diversos setores de atuação das empresas foram categorizados nos três principais setores de atividade econômica: comércio, indústria e serviço.

Quanto ao tamanho da firma, por meio de quartis, as empresas foram categorizadas em: pequena, média-pequena, média-grande e grande, conforme Quadro 3. 
Quadro 3 - Categorização do tamanho

\begin{tabular}{|l|c|}
\hline \multicolumn{1}{|c|}{ Ativo Total em milhares de reais } & Categoria \\
\hline Até $R \$ 3.716 .749,00$ & Pequena \\
\hline Entre $R \$ 3.716 .749,01$ e $R \$ 22.242 .998,00$ & Média-pequena \\
\hline Entre $R \$ 9.454 .604,01$ e $R \$ 22.242 .998,00$ & Média-grande \\
\hline Acima de $R \$ 22.242 .998,01$ & Grande \\
\hline
\end{tabular}

Fonte: Elaborado pelos autores.

A distribuição do valor adicionado foi categorizada em empregados, governo, financiadores e proprietários. Tais categorias foram obtidas da seguinte forma: se a empresa distribuiu maior valor adicionado para os empregados, esta é categorizada "empregados"; sendo aplicado o mesmo critério para governo, financiadores e proprietários. A Tabela 1 apresenta um exemplo da categorização do valor adicionado.

Tabela 1 - Categorização do valor adicionado

\begin{tabular}{c|c|c|c|c|c}
\hline Caso & Empregados & Governo & Financiadores & Proprietários & Valor Adicionado \\
\hline 1 & $\mathbf{5 0} \%$ & $14 \%$ & $21 \%$ & $15 \%$ & Empregados \\
\hline 2 & $10 \%$ & $\mathbf{5 3 \%}$ & $5 \%$ & $32 \%$ & Governo \\
\hline 3 & $11 \%$ & $19 \%$ & $\mathbf{4 2 \%}$ & $\mathbf{2 8 \%}$ & Financiadores \\
\hline 4 & $4 \%$ & $37 \%$ & $5 \%$ & $\mathbf{5 4 \%}$ & Proprietários \\
\hline
\end{tabular}

Fonte: Elaborado pelos autores.

Com base na Tabela 1, verifica-se que o caso 1 é categorizado como empregados, pois $50 \%$ do valor adicionado foram distribuídos para esse agente econômico, sendo superior ao destinado para os demais agentes. Os casos 2, 3 e 4 foram categorizados em governo, financiadores e proprietários, respectivamente, pois esses agentes são aqueles que recebem maior distribuição do valor acionado, em cada caso.

O tratamento dos dados, na Correlação de Pearson e na Análise de Correspondência Múltipla, foi realizado com o auxílio do aplicativo Statistical Package for the Social Sciences (SPSS), versão 21.

\section{DISCUSSÃO DOS RESULTADOS}

A partir dos dados coletados, com valores em milhares de reais, nas DVAs, foi possível realizar uma análise da evolução da parcela da riqueza distribuída entre os diversos contratos das organizações, verificando-se o comportamento dessa distribuição, tanto em relação ao período analisado, quanto em relação ao contexto societário das entidades que compõem a amostra (Figura 1).

Figura 1 - Distribuição do valor adicionado por agente contratual e por exercício 


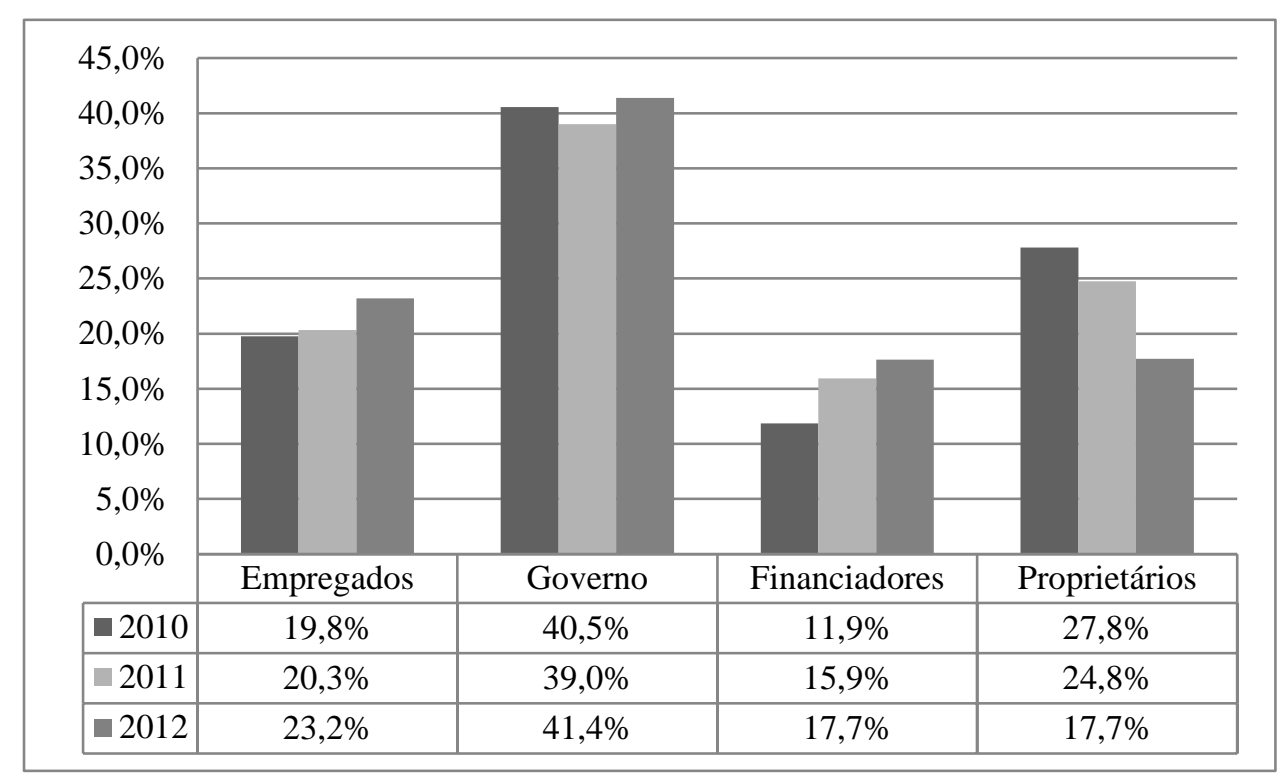

Fonte: Dados da pesquisa.

Comparando-se a parcela da riqueza distribuída entre os agentes contratuais nos exercícios de 2010 e 2012, verifica-se que houve um acréscimo na parcela da riqueza distribuída para os empregados, governo e financiadores. Percebe-se ainda, que o governo, que corresponde à distribuição do valor adicionado sob a forma de tributos e contribuições, é o agente contratual para o qual se distribui a maior proporção da riqueza gerada pelas empresas, sendo esse resultado corroborado pela literatura (CUNHA; RIBEIRO; SANTOS, 2005; SANTOS; SILVA, 2009; FOLLMANN; PAIVA; SOARES, 2010; SANTOS et al., 2013). Dentre os quatro principais agentes contratuais, o grupo dos proprietários foi o único em que houve um decréscimo na participação da riqueza gerada.

A Figura 2 apresenta a parcela da riqueza distribuída entre os principais agentes contratuais das empresas em relação ao seu contexto societário, nos três exercícios analisados.

Figura 2 - Distribuição do valor adicionado por agente contratual e por contexto societário

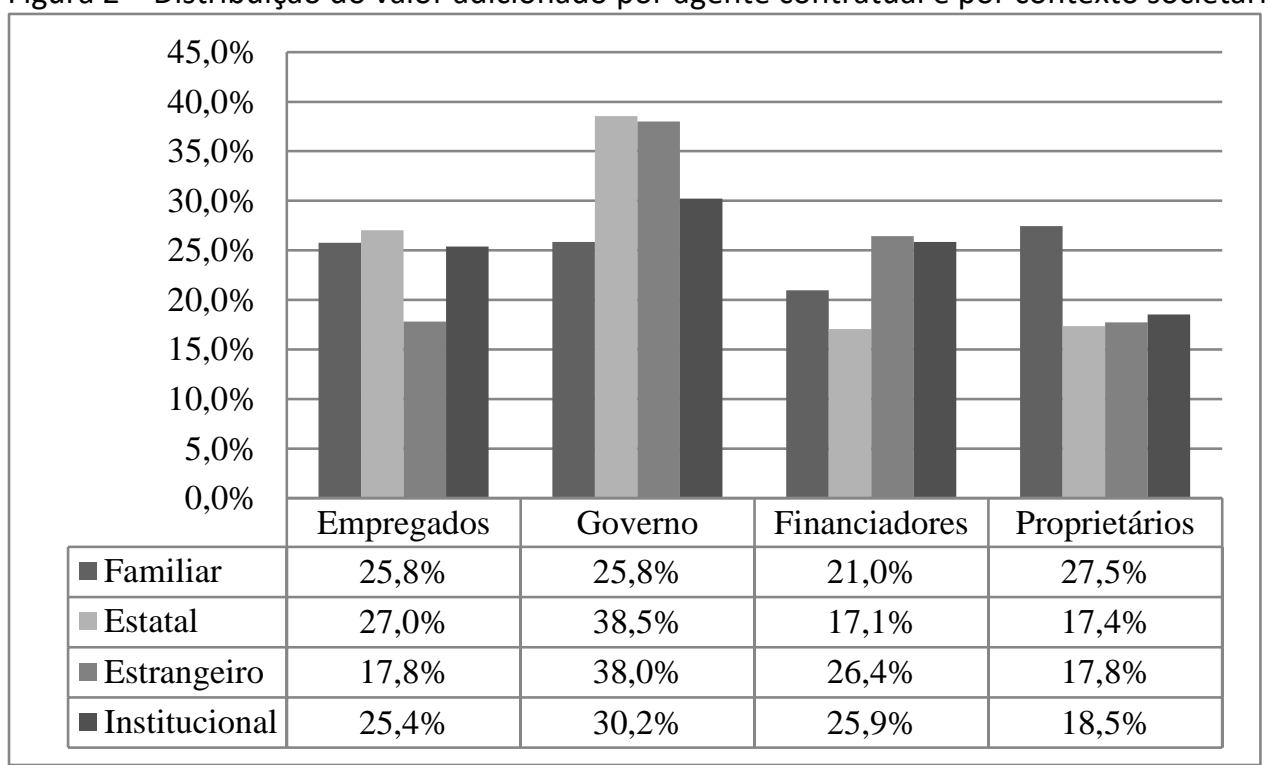

Fonte: Dados da pesquisa. 
No que diz respeito à distribuição da riqueza com os diversos contratos da empresa, em relação ao seu contexto societário, observa-se que no contexto familiar a parcela da riqueza distribuída entre os agentes contratuais é praticamente semelhante. Destaca-se também que dentre os agentes contratuais, o governo foi o que mais absorveu recursos, conforme já apontado na Figura 1, exceto quanto às empresas representadas pelo contexto familiar em que se observa maior distribuição para os proprietários. Convém salientar ainda que, de acordo com a Figura 2, após o contrato governo, somente o contexto estatal gasta mais com empregados. Chan, Silva e Martins (2007) obtiveram resultados que coadunam com os do presente estudo, indicando que as empresas privadas distribuem com empregados uma proporção menor da riqueza, comparativamente às estatais. Ao realizar pesquisa em empresas do setor elétrico, Machado et al. (2009) atribuíram a origem dessa diferença à maior quantidade de funcionários, assim como à maior remuneração proporcionada pelas empresas estatais.

Após a análise dos dados da riqueza distribuída entre os diversos agentes contratuais, considerando ainda o contexto societário das empresas, foi utilizada a Análise de Correspondência Múltipla para atender o objetivo adicional de verificar a associação entre o setor de atividade econômica, o tamanho da firma e a distribuição do valor adicionado. Como pressuposto da utilização da ANACOR, é necessário realizar o teste Qui-quadrado (Tabela 2) com o objetivo de analisar a interdependência entre as variáveis estudadas.

Tabela 2 - Teste Qui-quadrado

\begin{tabular}{|c|c|c|}
\hline Relação & Qui-quadrado & Significância \\
\hline Valor adicionado $x$ Setor de atividade econômica & 39,027 & $0,000^{* * *}$ \\
\hline Valor adicionado $\mathrm{x}$ Tamanho da firma & 29,984 & $0,000^{* * *}$ \\
\hline Setor de atividade econômica $\times$ Tamanho da Firma & 14,558 & $0,024^{* *}$ \\
\hline
\end{tabular}

$\left({ }^{* *}\right)$ Significante ao nível de $\left.5 \% ;{ }^{* * *}\right)$ Significante ao nível de $1 \%$.

Fonte: Dados da pesquisa.

Com base nos valores demonstrados na Tabela 2, pode-se observar a interdependência entre as variáveis distribuição do valor adicionado, setor de atividade econômica e tamanho da firma, pois demonstram significância entre $5 \%$ e $1 \%$. Com base nesses resultados, pode-se prosseguir com a Análise de Correspondência Múltipla. Assim, a Figura 3 mostra o mapa perceptual que evidencia a associação entre as variáveis setor de atividade econômica, tamanho da empresa e distribuição do valor adicionado.

Figura 3 - Mapa perceptual da associação entre o setor, tamanho e o valor adicionado 


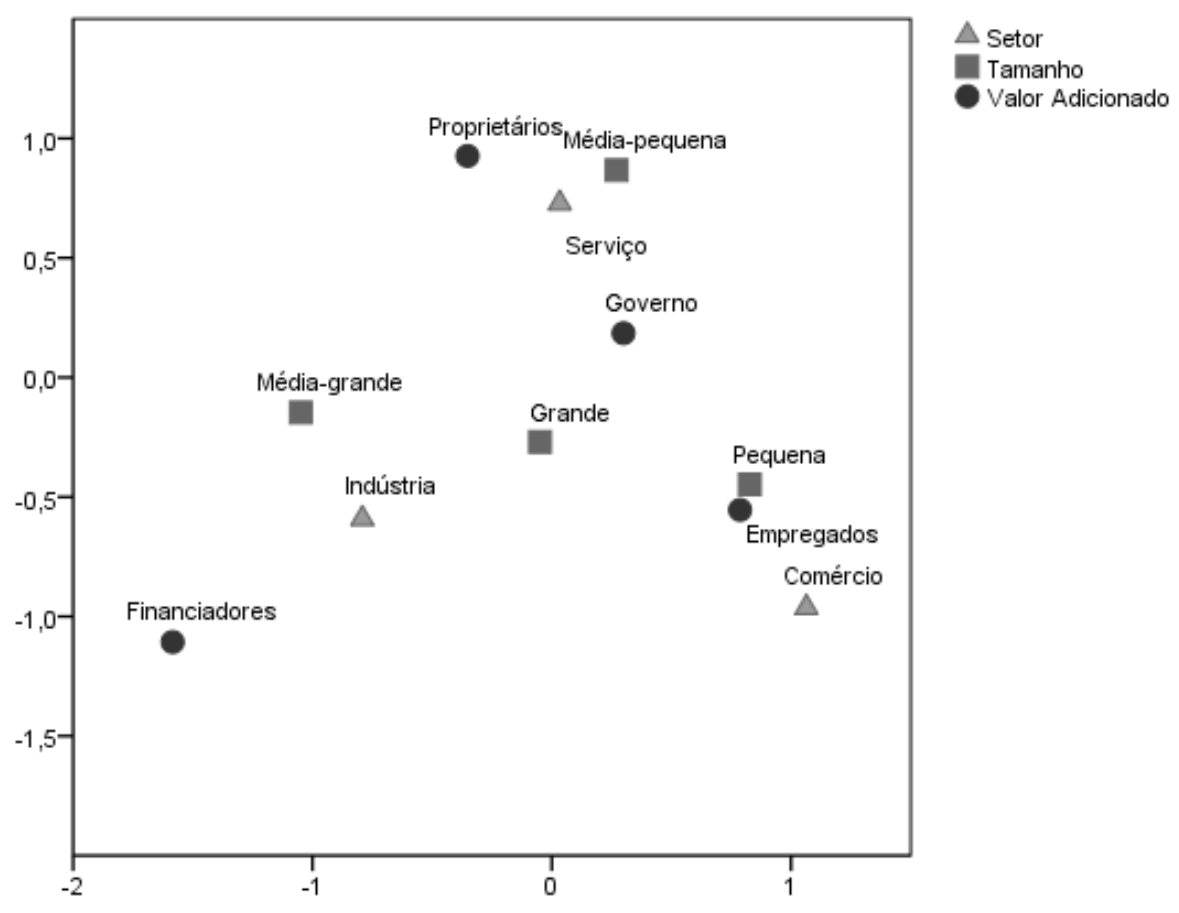

Fonte: Dados da pesquisa.

Com base na Figura 3, percebe-se duas associações. A primeira associação que se visualiza no mapa ocorre entre empresas pequenas, com maior distribuição do valor adicionado para empregados e o setor comércio. Assim, pode-se entender que empresas pequenas e do setor comércio têm uma maior preocupação com empregados, pois há uma maior destinação da riqueza para remuneração direta e benefícios. Esse resultado difere do encontrado por Cunha, Ribeiro e Santos (2005), no qual o setor que mais distribui riqueza para empregados é o de serviço.

A segunda associação verificada na Figura 3 está entre empresas média-pequenas, maior distribuição do valor adicionado para proprietários e o setor serviço. Pode-se então, inferir que as empresas média-pequenas do setor serviço distribuem parcela maior da riqueza aos proprietários, por meio de dividendos e juros sobre o capital próprio. Ao analisar a distribuição do valor adicionado por setor de atividade econômica, Boscov e Bispo (2010) identificaram que o setor que mais distribui riqueza para os proprietários é o industrial.

Antes de proceder com o teste de Correlação de Pearson, realizou-se uma análise descritiva dos dados do valor adicionado distribuído aos agentes econômicos, a fim de se compreender a sua distribuição (Tabela 3).

Tabela 3 - Estatística descritiva dos dados

\begin{tabular}{l|c|c|c|c|c|c}
\hline \multicolumn{1}{c|}{ Variáveis } & N & Mínimo & Máximo & Média & Desvio-padrão & $\begin{array}{c}\text { Coeficiente de } \\
\text { variação }\end{array}$ \\
\hline Empregados & 297 & $-19,4 \%$ & $92,8 \%$ & $24,3 \%$ & $17,2 \%$ & $70,8 \%$ \\
\hline Governo & 297 & $-70,3 \%$ & $84,5 \%$ & $31,8 \%$ & $18,9 \%$ & $59,4 \%$ \\
\hline Financiadores & 297 & $-36,0 \%$ & $321,5 \%$ & $21,7 \%$ & $27,7 \%$ & $127,9 \%$ \\
\hline Proprietários & 297 & $-185,1 \%$ & $193,0 \%$ & $22,3 \%$ & $27,9 \%$ & $125,4 \%$ \\
\hline
\end{tabular}

Fonte: Dados da pesquisa. 
Pela Tabela 3, constata-se que governo e proprietários apresentam as menores proporções da distribuição do valor adicionado, seguidos de financiadores e empregados, respectivamente. Quanto às maiores parcelas da distribuição do valor adicionado, destacam-se os financiadores, seguido de proprietários, empregados e governo, nessa ordem. Destarte, os agentes econômicos financiadores e proprietários são os dois extremos quanto à distribuição do valor adicionado; esse resultado se reflete no coeficiente de variação, mostrando que na amostra não há determinada homogeneidade na distribuição do valor adicionado para esses agentes econômicos.

Contudo, observando-se a média, os resultados refletem o que já fora apresentado nas Figuras 1 e 2 , no qual o governo, que corresponde à distribuição do valor adicionado sob a forma de tributos e contribuições, é o agente contratual para o qual se distribui a maior proporção da riqueza gerada pelas empresas, corroborando com os resultados de Cunha, Ribeiro e Santos (2005), Santos e Silva (2009) e Follmann, Paiva e Soares (2010). Depois do governo, os empregados representam o agente econômico que recebe maior distribuição do resultado. Esses dois agentes, se comparados aos financiadores e proprietários, possuem certa homogeneidade na distribuição do valor adicionado. Entretanto, de modo geral, as variáveis apresentaram um elevado coeficiente de variação, demonstrando, assim, uma baixa homogeneidade dos dados, sugerindo que as empresas não adotam políticas semelhantes quanto à distribuição da riqueza criada aos agentes contratuais.

Uma vez apresentada a análise descritiva dos dados, passou-se à análise da Correlação de Pearson que, neste estudo, foi aplicada para obter resultados que possibilitem aceitar ou refutar a hipótese do estudo. A Tabela 3 reúne os resultados estatísticos da Correlação de Pearson. Espera-se que a distribuição do valor adicionado com os principais agentes contratuais - empregados, governo, financiadores e proprietários - seja relacionada com o seu contexto societário, conforme hipótese apresentada.

Tabela 3 - Resultados da Correlação de Pearson

\begin{tabular}{l|l|c|c|c|c}
\hline \multicolumn{2}{l|}{ Variáveis } & Familiar & Estatal & Estrangeiro & Institucional \\
\hline \multirow{2}{*}{ Empregados } & Coeficiente de Pearson & 0,056 & 0,062 & $-0,231^{* * *}$ & 0,023 \\
\cline { 2 - 6 } & Significância & 0,336 & 0,290 & 0,000 & 0,694 \\
\hline \multirow{2}{*}{ Governo } & Coeficiente de Pearson & $-0,212^{* * *}$ & $0,140^{* *}$ & $0,203^{* * *}$ & $-0,030$ \\
\cline { 2 - 6 } & Significância & 0,000 & 0,016 & 0,000 & 0,607 \\
\hline \multirow{2}{*}{ Financiadores } & Coeficiente de Pearson & $-0,017$ & $-0,065$ & $0,105^{*}$ & 0,056 \\
\cline { 2 - 6 } & Significância & 0,769 & 0,267 & 0,070 & 0,333 \\
\hline \multirow{2}{*}{ Proprietários } & Coeficiente de Pearson & $0,126^{* *}$ & $-0,068$ & $-0,099^{*}$ & $-0,050$ \\
\cline { 2 - 6 } & Significância & 0,030 & 0,240 & 0,088 & 0,392 \\
\hline
\end{tabular}

$\left({ }^{*}\right)$ Significante ao nível de 10\%; $\left(^{* *}\right)$ Significante ao nível de 5\%; $\left({ }^{* *}\right)$ Significante ao nível de $1 \%$.

Fonte: Dados da pesquisa.

Observando o contrato relativo aos empregados, o contexto societário estrangeiro demonstrou significância negativa e um fraco grau de relação entre as variáveis, ou seja, as empresas estrangeiras destacam uma menor proporção da sua riqueza para empregados. Destarte, pode-se inferir que a distribuição da riqueza com os empregados se relaciona com o contexto societário estrangeiro, confirmando-se a hipótese H1a, para tal contexto.

Quanto ao contrato relativo ao governo, os contextos societários familiar, estatal e estrangeiro demonstraram significância, sendo esta negativa para o contexto familiar e positiva nos contextos 
estatal e estrangeiro, sendo que em todos os contextos societários, o grau de relação das variáveis é fraco. Destarte, as empresas estatais e estrangeiras distribuem uma maior proporção da riqueza com o governo, em contraponto, as empresas familiares distribuem menor riqueza. Portanto, aceita-se a hipótese $\mathrm{H} 1 \mathrm{~b}$ do estudo, em que o contexto societário familiar, estatal e estrangeiro se relacionam com a riqueza distribuída com o governo.

Por sua vez, no contrato relativo aos financiadores, o contexto societário estrangeiro demonstrou significância positiva com um fraco grau de relação entre as variáveis. Dessa forma, as empresas estrangeiras separam uma maior proporção da sua riqueza para os financiadores. Assim, pode-se aceitar a hipótese $\mathrm{H} 1 \mathrm{c}$, levando-se em conta que o contexto societário estrangeiro se relaciona com a riqueza distribuída com os financiadores.

Verifica-se ainda, quanto ao contrato relativo aos proprietários, que os contextos societários familiar e estrangeiro demonstraram significância positiva e negativa, respectivamente, ambas com fraco grau de relação entre as variáveis. Desse modo, pode-se inferir que as empresas familiares destacam uma maior proporção da sua riqueza para os proprietários, sugerindo que tais empresas estão preocupadas com os lucros e os dividendos para os acionistas. Por outro lado, empresas estrangeiras destinam menor parcela da riqueza para os proprietários. Dessa forma, aceita-se a hipótese H1d do estudo, na medida em que a distribuição da riqueza com os proprietários está relacionada com o contexto societário familiar e estrangeiro.

Cabe ressaltar que não foi observada relação entre a distribuição do valor adicionado aos agentes contratuais e o contexto societário institucional.

Pode afirmar, portanto, que todas as hipóteses do estudo foram aceitas, em que a distribuição do valor adicionado entre os principais agentes contratuais - empregados, governo, financiadores e proprietários - está relacionada com o contexto societário. Esse resultado indica que o contexto societário determina a distribuição da riqueza gerada (SANTOS; CHAN; SILVA, 2007; BRAGA, 2008; MACHADO et al., 2009). Assim, cada um dos stakeholders - no estudo representados por empregados, governo, financiadores e proprietários -, por meio de contrato implícito ou explícito, contribui de alguma forma na geração da riqueza para a firma e recebe uma parcela correspondente, confirmando os preceitos da Teoria Contratual da Firma, demonstrados por Lopes e ludícibus (2012), sendo essa parcela influenciada pelo contexto societário (PEDERSEN; THOMSEN, 2003; OKIMURA; SILVEIRA; ROCHA, 2007).

\section{CONSIDERAÇÕES FINAIS}

O presente estudo teve por objetivo analisar a relação entre a distribuição do valor adicionado com os principais agentes contratuais das empresas e o seu contexto societário, representado pelo maior acionista controlador. Para tanto, efetuou-se uma análise de dados extraídos das demonstrações financeiras padronizadas e formulários de referência referentes aos exercícios de 2010, 2011 e 2012, de uma amostra que reuniu 99 das 100 maiores empresas de capital aberto do Brasil por valor de mercado, segundo a classificação da revista Exame Melhores e Maiores, edição de 2013.

Por meio da análise descritiva dos dados, verificou-se que, em geral, o governo foi o agente contratual que mais absorveu riqueza das empresas, mesmo sofrendo uma diminuição gradual nos três anos analisados.

Os resultados da aplicação da Análise de Correspondência Múltipla demonstraram que empresas pequenas e do setor comércio têm uma maior preocupação com empregados, na medida em que distribuem maior parcela da riqueza a esses agentes, e que as empresas média-pequenas e do setor serviço distribuem maior parte da riqueza para os proprietários. 
Utilizando-se a Correlação de Pearson, observou-se que nem todos os contextos societários demonstraram possuir relação significante com as variáveis representadas pela distribuição do valor adicionado para cada tipo de contrato: empregados, governo, financiadores e proprietários. 0 contrato relativo aos empregados apresentou relação negativa com o contexto societário estrangeiro. Já a distribuição ao agente contratual governo apresentou relação negativa com o contexto societário familiar, e positiva com os contextos societários estatal e estrangeiro. Quanto ao contrato relativo aos financiadores, o contexto societário estrangeiro demonstrou significância positiva. E a distribuição da riqueza para os proprietários demonstrou relação positiva com o contexto societário familiar, e negativa com o contexto societário estrangeiro.

Destarte, à luz da Teoria Contratual da Firma, constatou-se que a hipótese do estudo foi aceita, na medida em que a distribuição do valor adicionado com os principais agentes contratuais apresentados na DVA - empregados, governo, financiadores e proprietários - está relacionada com o contexto societário das empresas, definido a partir do seu maior acionista controlador.

Cabe ressaltar a importância do presente estudo, ao apresentar o tema Demonstração do Valor Adicionado sob a perspectiva da Teoria Contratual da Firma, além da análise estatística que possibilitou determinar a relação dos contratos firmados por uma empresa com seus vários agentes, em diversos contextos societários. Destaca-se ainda que esses achados podem contribuir para o processo decisório dos diversos stakeholders, pois possibilitam uma reflexão quanto à destinação da riqueza gerada pelas empresas.

Contudo, os resultados apresentados estão condicionados à escolha da amostra, limitada às 99 maiores empresas de capital aberto no Brasil, e ao período de três anos utilizados no estudo. Assim, sugere-se, para futuras pesquisas, a utilização de um maior número de empresas, a ampliação do período de análise e a aplicação de um teste estatístico mais robusto, além da adoção de abordagem diversa do presente estudo, levando em conta contextos empresariais diferentes, o que trará a possibilidade de se verificar semelhanças ou divergências com os resultados aqui encontrados.

\section{REFERENNCIAS}

BARBOSA, R.; ARAÚJO, T. S.; PRIETO, M. F.; ANDRADE, M. E. M. C. Demonstração do valor adicionado: uma análise do setor de saúde. In: CONGRESSO UFV DE ADMINISTRAÇÃO E CONTABILIDADE, 5., 2012, Viçosa. Anais... Viçosa: UFV, 2012.

BISPO, J. S.; CALIJURI, M. S. S.; LIMA, I. S. A importância dos dados contábeis para a relação entre carga tributária, tamanho e setor econômico das empresas brasileiras. Revista de Informação Contábil-RIC, v. 3, n. 3, p. 25-43, 2009.

BOSCOV, C.; BISPO, J. S. A comparação da distribuição de riqueza gerada entre os setores de serviço, comércio e indústria. ConTexto, v. 10, n. 17, p. 59-70, 2010.

BRAGA, P. T. S. Demonstração do valor adicionado (DVA): um estudo comparativo do perfil de distribuição de riqueza pelas empresas estatais e privadas do Brasil. 2008. 98 f. Dissertação (Mestrado em Ciências Contábeis) - Programa Multi-institucional e Inter-regional de Pós-Graduação em Ciências Contábeis, Universidade de Brasília, Universidade Federal da Paraíba e Universidade Federal do Rio Grande do Norte, Natal, 2008.

BRASIL. Lei $n^{\circ} 11.638$, de 28 de dezembro de 2007. Altera e revoga dispositivos da Lei $n^{\circ} 6.404$, de 15 de dezembro de 1976. Disponível em: <https://www.planalto.gov.br>. Acesso em: 23 fev. 2014.

CAIXE, D. F.; KRAUTER, E. A influência da estrutura de propriedade e controle sobre o valor de mercado corporativo no Brasil. Revista Contabilidade \& Finanças, v. 24, n. 62, 142-153, 2013. 
CAMPOS, T. C. Estrutura de propriedade e desempenho econômico: uma avaliação empírica para as empresas de capital aberto no Brasil. Revista de Administração USP - RAUSP, v. 41, n. 4, p. 369-380, 2006.

CARVALHAL-DA-SILVA, A. L. Governança corporativa, valor, alavancagem e política de dividendos das empresas brasileiras. Revista de Administração USP - RAUSP, v. 39, n. 4, p. 348-361, 2004.

CHAN, B. L.; SILVA, F. L.; MARTINS, G. A. Destinação de riqueza aos acionistas e aos empregados: comparação entre empresas estatais e privadas. Revista de Administração Contemporânea - RAC, v. 11, n. 4, p. 199-218, 2007.

COLLIS, J.; HUSSEY, R. Pesquisa em administração: um guia prático para os alunos de graduação e pós-graduação. 2. ed. Porto Alegre: Bookman, 2005.

COSTA, C. L. O.; GUIMARÃES, T. R.; MELLO, L. C. B. B. Os possíveis benefícios gerados pela obrigatoriedade da publicação da demonstração do valor adicionado pelas empresas de capital aberto. Revista de Contabilidade do Mestrado em Ciências Contábeis da UERJ (online), v. 18, n. 3, p. 77-93, set./dez. 2013.

COZENSA, J. P. A eficácia informativa da demonstração do valor adicionado. Revista Contabilidade e Finanças - USP, Edição Comemorativa, p. 7-29, 2003.

CPC - Comitê de Pronunciamentos Contábeis. Pronunciamento Técnico CPC 09: Demonstração do Valor Adicionado. (2008). Comitê de Pronunciamentos Contábeis. Disponível em: <http://www.cpc.org.br>. Acesso em: 3 fev. 2014.

CUNHA, J. V. A.; RIBEIRO, M. S.; SANTOS, A. A demonstração do valor adicionado como instrumento de mensuração da distribuição da riqueza. Revista de Contabilidade \& Finanças - USP, n. 37, p. 7-23, 2005.

DAMI, A. B. T.; ROGERS, P.; RIBEIRO, K. C. S. Estrutura de propriedade no Brasil: evidências empíricas do grau de concentração acionária. Revista Contemporânea de Economia e Gestão, v. 5, n. 2, p. 2130, 2007.

DANCEY, C.; REIDY, J. Estatística sem matemática para psicologia: usando SPSS para windows. Porto Alegre: Artmed, 2006.

DANI, A. C.; BECK, F.; ALMEIDA-SANTOS, P. S.; LAVARDA, C. E. F. Análise da estrutura de propriedade das empresas listadas no ISE por meio da aplicação de redes sociais. Revista de Educação e Pesquisa em Contabilidade, v. 7, n. 3, p. 240-258, jul./set. 2013.

DE LUCA, M. M. M.; CUNHA, J. V. A.; RIBEIRO, M. S.; OLIVEIRA, M. C. Demonstração do valor adicionado. 2. ed. São Paulo: Atlas, 2009.

EVRAERT, S; RIAHI-BELKAOUI, A. Usefulness of value added reporting: a review and synthesis of the literature. Managerial Finance, v. 24, n. 11, p. 1-15, 1998.

EXAME. Melhores e maiores: as 1.000 maiores empresas do Brasil, São Paulo: Abril, 2013.

FÁVERO, L. P. L.; BELFIORE, P. P.; CHAN, B. L.; SILVA, F. L. Análise de dados: modelagem multivariada para tomada de decisões. São Paulo: Campus, 2009.

FOLLMANN, D. A.; CASAGRANDE, M. D. H.; PAIVA, K. S. E. Distribuição do valor adicionado: a quem se destina a riqueza gerada nas empresas do Novo Mercado? In: CONGRESSO UFSC DE CONTROLADORIA E FINANÇAS, 11., 2009. Anais... Florianópolis: UFSC, 2009. 
PAIVA, K. S. E.; SOARES, S. V. Distribuição do valor adicionado nas empresas do Novo Mercado: análise setorial da destinação da riqueza em 2008 e 2009. In: SEMINÁRIOS EM ADMINISTRAÇÃO - SEMEAD, 13., 2010. Anais... São Paulo: FEA-USP, 2010.

FONSECA, M. V.; PAIVA, S. B. Demonstração do valor adicionado: uma análise do valor adicionado do Banco do Brasil no período 2008-2010. VEREDAS FAVIP - Revista Eletrônica de Ciências, v. 5, n. 2, p. 51-65, 2012

FREGONESI, M. S. F. A. Investimentos socioambientais na demonstração do valor adicionado: formação ou distribuição do valor adicionado?. 2009. 222 f. Tese (Doutorado em Controladoria e Contabilidade) - Faculdade de Economia, Administração e Contabilidade, Universidade de São Paulo, São Paulo, 2009.

HAIR JR., J. F.; WOLFINBARGER, M.; ORTINAU, D. J.; BUSH, R. P. Fundamentos de pesquisa de marketing. Porto Alegre: Bookman, 2008.

IBGC - Instituto Brasileiro de Governança Corporativa. Código das melhores práticas de governança corporativa. 4. ed. São Paulo: IBGC, 2009.

LEAL, R.; CARVALHAL-DA-SILVA, A. Corporate governance index, firm valuation and performance in Brasil. Revista Brasileira de Finanças, v. 3, n. 1, p. 1-18, 2005.

LOPES, A. B.; IUDÍCIBUS, S. Teoria avançada da contabilidade. 2. ed. São Paulo: Atlas, 2012.

; MARTINS, E. Teoria da contabilidade: uma nova abordagem. 1. ed. São Paulo: Atlas, 2012.

MACHADO, E. A.; MORCH, R. B.; VIANNA, D. S. C.; SANTOS, R.; SIQUEIRA, J. R. M. Destinação de riqueza aos empregados no Brasil: comparação entre empresas estatais e privadas do setor elétrico (2004-2007). Revista Contabilidade \& Finanças, v. 20, n. 50, p. 110-122, 2009.

MARTINS, G. A.; THEÓPHILO, C. N. Metodologia da investigação científica para ciências sociais aplicadas. São Paulo: Atlas, 2009.

MOORE, D. S. The basic practice of statistics. New York: Freeman, 2007.

OKIMURA, R. T.; SILVEIRA, A. M.; ROCHA, K. C. Estrutura de propriedade e desempenho corporativo no Brasil. Revista de Administração Contemporânea - RAC, v. 1, n. 1, p. 119-135, 2007.

OLIVEIRA, R. M.; SILVA JÚNIOR, A.; SILVA, A. R. L. Relação entre o investimento social corporativo e o valor das empresas brasileiras. Revista de Educação e Pesquisa em Contabilidade - REPEC, v. 4, n. 2, p. $62-80,2010$.

PEDERSEN, T.; THOMSEN, S. Ownership structure and value of the largest European firms: the importance of owner identity. Journal of Management and Governance, v. 7, p. 27-55, 2003.

PEREIRA, A. G.; BRUNI, A. L.; ROCHA, J. S.; LIMA FILHO, R. N.; FARIA, J. A. Teoria dos contratos, governança corporativa e auditoria: delineamentos para a discussão em teoria da contabilidade. In: SIMPÓSIO DE EXCELÊNCIA EM GESTÃO E TECNOLOGIA, 7., 2010. Anais... Rio de Janeiro: AEDB, 2010.

PINTO, L. J. S.; FREIRE, F. S. Análise do valor adicionado e de sua distribuição: um estudo nos bancos listados na Bovespa com uso da Anova. Enfoque: Reflexão Contábil, v. 32, n. 1, p. 65- 75, 2013.

RIAHI-BELKAOUI, A.; FEKRAT, M. A. The magic in value added: merits of derived accounting indicator numbers. Managerial Finance, v. 20, n. 9, p. 3-15, 1994.

SAMPIERI, R. H.; COLLADO, C. F.; LÚCIO, P. B. Metodologia de pesquisa. 3. ed. São Paulo: McGraw Hill, 2013. 
SANTOS, A. Demonstração do valor adicionado: como elaborar e analisar a DVA. 2. ed. São Paulo: Atlas, 2007.

; CHAN, B. L.; SILVA, F. L. Análise dos impactos da privatização na distribuição de riqueza a partir da demonstração do valor adicionado. Revista Universo Contábil, v. 3, n. 1, p. 06-21, 2007.

; CUNHA, J. V. A.; DE LUCA, M. M. M.; RIBEIRO, M. S. A economia das empresas nos governos FHC e Lula: uma análise a partir da demonstração do valor adicionado. Revista de Contabilidade e Controladoria, v. 5, n. 1, p. 47-64, 2013.

SANTOS, M. I. C.; SILVA, M. S. DVA como ferramenta na medição da riqueza no setor de telefonia no Brasil. Pensar Contábil, v. 11, n. 46, p. 39-45, 2009.

SCHERER, L. M. Valor adicionado: análise empírica de sua relevância para as companhias abertas que publicam a demonstração do valor adicionado. 2006. 129 f. Tese (Doutorado em Controladoria e Contabilidade) - Faculdade de Economia, Administração e Contabilidade, Universidade de São Paulo, São Paulo, 2006.

SILVA, J. O.; HAUSSMANN, D. C. S.; BEUREN, I. M. Reflexos das alterações da Lei no 11.638/07 nas informações trimestrais de empresas de capital aberto. Revista de Contabilidade e Controladoria, $v$. 4, n. 1, p. 62-77, 2012.

SUNDER, S. Teoria da contabilidade e do controle. São Paulo: Atlas, 2014.

VASCONCELOS, A. C.; BRANDÃO, J. W.; AQUINO, R. R. N.; MIRANDA, R.; O.; DE LUCA, M. M. M. Distribuição do valor adicionado com os empregados nas empresas indicadas como as melhores para se trabalhar. In: CONGRESSO USP DE CONTROLADORIA E CONTABILIDADE, 13., 2013, São Paulo. Anais... São Paulo: USP, 2013.

VIEIRA, P. S. Verdades e mitos na interpretação da demonstração do valor adicionado. 2010. 143 f. Dissertação (Mestrado em Controladoria e Contabilidade) - Curso de Pós-Graduação em Controladoria e Contabilidade, Faculdade de Economia, Administração e Contabilidade, Universidade de São Paulo, São Paulo, 2010.

VIEIRA, S. J. Modelo de análise da demonstração do valor adicionado para a gestão das empresas. 2004. 137 f. Dissertação (Mestrado em Engenharia de Produção) - Programa de Pós-Graduação em Engenharia de Produção, Universidade Federal de Santa Catarina, Florianópolis, 2004.

ZYLBERSZTAJN, D. Papel dos contratos na coordenação agro-industrial: um olhar além dos mercados. Revista de Economia \& Sociologia Rural, v. 43, n. 3, p. 385-420, 2005. 